\title{
Comunicação
}

[Communication]

\section{Efeito da administração de tiroxina sobre o peso corporal e sobre algumas características físico-químicas e histológicas do músculo Longissimus dorsi de marrãs com 70 dias de gestação}

\author{
[Effect of the thyroxine administration on body weight and on some physicochemical and \\ histological characteristics of the Longissimus dorsi muscle in gilts \\ at 70 days of gestation]

\section{W.L. Wendling, C.A. Souza, J.F. Silva, N.M. Ocarino, J.N. Boeloni,} \\ E.F. Nascimento, I.J. Silva, A.L. Oliveira, R. Serakides* \\ Universidade Federal de Minas Gerais \\ Av. Antônio Carlos, 6627 \\ 31270-901 - Belo Horizonte, MG
}

\begin{abstract}
Na economia global, a qualidade da carne suína tem considerável importância em todos os segmentos da indústria (Cassens, 2000). É fundamental que a indústria conheça os fatores externos e internos que podem alterar as características da carne, disponibilizando para o consumo um produto com qualidade para atender a demanda e o desejo dos consumidores no que se refere as suas qualidades sanitárias, nutritivas e organolépticas (Bryhni et al., 2002).
\end{abstract}

A qualidade da carne depende de fatores como genética, alimentação, idade, sexo e até de fatores hormonais como é o caso do cortisol, que, em elevadas concentrações, está associado à redução brusca do $\mathrm{pH}$ da carne, alterando suas características organolépticas, sensoriais e físicoquímicas. O estresse ativa o eixo hipotálamohipófise-adrenal e aumenta a secreção de cortisol, provocando miólise (Odedra et al., 1983). Em ratos, o cortisol aumenta a degradação das miofibrilas na presença do hormônio tireoidiano (Hayashi et al., 1986). Apesar de a administração de cortisol estar associada a elevadas concentrações de tri-iodotironina (T3) em suínos com carne pálida, mole e exsudativa (PSE) (Yoshioka et al., 2005), não se sabe se a T3 participa da gênese da PSE. Em leitões, a administração de tireoproteína aumentou o ganho de peso em aproximadamente $18 \%$ e melhorou a eficiência alimentar dos animais em 9\% (Peo e Hudman, 1960). Além disso, a administração de tiroxina (T4) tem sido utilizada na tentativa de melhorar os índices reprodutivos da marrã (Souza, 2009). Mas não há estudos da influência da T4 sobre o ganho de peso corporal e sobre algumas características físico-químicas e histológicas do músculo Longissimus dorsi de animais gestantes. Assim, o objetivo do presente estudo, como complementação ao trabalho de Souza (2009), é o de verificar o efeito da administração de T4 sobre o peso corporal durante a gestação e sobre algumas características físico-químicas e histológicas do músculo Longissimus dorsi de marrãs com 70 dias de gestação.

Foram utilizadas 20 marrãs F1 (3/4 Landrace X 1/4 Large White) inicialmente com 120 dias de idade. O ensaio foi aprovado pelo Comitê de Ética em Experimentação Animal da UFMG (protocolo 135/2007).

As marrãs, meio-irmãs, filhas do mesmo varrão (3/4 Landrace X 1/4 Large White), foram alojadas em baias individuais. $\mathrm{Na}$ fase de prégestação, ingeriram 4,0kg/dia de ração para suíno em crescimento e, após o primeiro cio, passaram a receber ração para lactação e gestação em forma de flushing, à vontade, até o dia da inseminação. Após a inseminação, foi realizada a troca gradativa, durante três dias, para ração de suíno em gestação, restringindo o consumo para até $1,8 \mathrm{~kg} /$ dia nos primeiros 30 dias da gestação e

Recebido em 1 de julho de 2009

Aceito em 16 de julho de 2010

Autor para correspondência (corresponding author)

E-mail: serakidesufmg@gmail.com 
para $2,5 \mathrm{~kg} /$ dia até o abate. A água foi fornecida à vontade durante todo o experimento.

Após um período de 30 dias de adaptação, ou seja, aos 150 dias de idade, as marrãs foram separadas, ao acaso, em dois grupos de 10 animais, denominados tratado e controle. Antes do primeiro cio, o grupo tratado recebeu Ltiroxina (L-thyroxine, Sigma, St. Louis, EUA.) na ração, na dose diária única de $400 \mu \mathrm{g}$. A tiroxina foi administrada individualmente pela manhã, diluída em água destilada e misturada em uma pequena porção de ração, dentro de um recipiente, até que houvesse todo o consumo da droga. As marrãs do grupo-controle receberam a mesma quantidade de ração úmida, como placebo. A administração de tiroxina foi interrompida três dias antes do abate, realizado aos 70 dias de gestação.

No segundo cio, as marrãs foram inseminadas e, durante esse período, foi avaliado o ganho de peso das marrãs até os 70 dias de gestação, por meio da pesagem semanal dos animais. Os animais foram abatidos aos 70 dias de gestação.

Aos 70 dias de gestação, ou seja, no terço médio do período gestacional, todas as fêmeas foram abatidas por meio da insensibilização por choque e sangria. Foram colhidas amostras de sangue com heparina para obtenção do plasma, imediatamente antes da inseminação, para dosagem de T4 total pela técnica de quimioluminescência (Immulite-DPC, Los Angeles, EUA). As amostras foram estocadas a $20^{\circ} \mathrm{C}$ por cerca de 30 dias até as análises. Os coeficientes de variação intra e interensaio foram de $4 \%$ e $7 \%$, respectivamente.

Após o abate, uma amostra do músculo Longissimus dorsi foi retirada entre a primeira e terceira costelas, da hemicarcaça direita, para análise da retenção de água pelo método de prensagem. Uma fotografia digital foi feita da amostra prensada para posterior análise com programa específico (ImageJ®). Além da análise da retenção de água, foram determinados o $\mathrm{pH}$ e a temperatura das amostras, e a coloração e o odor, imediatamente após o abate.

Um fragmento do músculo foi fixado em formol a $10 \%$ neutro e tamponado, e processado pela técnica rotineira de inclusão em parafina. Cortes histológicos de $4 \mu \mathrm{m}$ foram corados pela hematoxilina-eosina para avaliação histomorfométrica. Em uma secção histológica, foi determinada a porcentagem de fibras musculares e de estroma em 30 campos aleatórios com auxílio de uma gratícula contendo 121 pontos, em aumento de $40 \times$.

O delineamento utilizado foi inteiramente ao acaso. Para cada variável foram determinados a média e o desvio-padrão. As médias foram comparadas pelo teste $t$, pelo programa estatístico Instat (Graph Pad Software, Versão 3.00, 32 Win 95/NT, Created December 23, 1997). Diferenças entre grupos foram consideradas significativas se $\mathrm{P}<0,05$.

As marrãs tratadas com tiroxina apresentaram sinais clínicos de hipertireoidismo, como aumento significativo dos níveis plasmáticos de T4 total (Tab. 1), discreta exoftalmia e alteração comportamental, caracterizada por agressividade e agitação. Durante todo o experimento, não se observou nenhuma anormalidade reprodutiva, e número e peso dos fetos não variaram entre grupos (Souza, 2009).

O peso dos animais durante o experimento e ao final do período experimental, ou seja, após aproximadamente cinco meses de hipertireoidismo, não diferiu significativamente entre grupos. $\mathrm{O}$ ganho de peso diário foi semelhante entre grupos (Tab. 1). Em estudos realizados em ratas, também não foi observada redução de peso decorrente do hipertireoidismo (Serakides et al., 2001; Freitas et al., 2007), ao contrário do que já foi relatado em humanos (Santos et al., 2002) e em gatos (Cardoso et al., 2005). Acredita-se que a redução de peso seja consequência de hipertireoidismo crônico e grave (Boelaert e Franklyn, 2005). Nesses casos, a quantidade de alimento ingerida não é suficiente para suprir o dispêndio calórico imposto pela doença e, dessa forma, o indivíduo entra em estado catabólico. É provável que a dose e/ou o período experimental de administração da tiroxina tenham sido insuficientes para reduzir o peso corporal. Mas a redução do peso corporal das marrãs do presente estudo seria um achado indesejável.

O conteúdo de água do músculo Longissimus dorsi não diferiu significativamente entre grupos, assim como o pH (Tab. 2). A determinação do $\mathrm{pH}$ é, provavelmente, uma das mais importantes 
medidas determinadas no músculo logo após o abate. Durante a conversão do músculo em carne, quando da instalação do rigor mortis, ocorre o abaixamento do $\mathrm{pH}$, devido à glicólise anaeróbica. A rápida glicólise imediatamente após o abate gera $\mathrm{pH}$ muscular ácido, geralmente menor que 5,8, o que caracteriza a carne pálida, mole e exsudativa (PSE). A determinação do $\mathrm{pH}$ serve para o diagnóstico da carne PSE, porém sua precisão aumenta quando aliada à medida de cor e à capacidade de retenção de água. No presente estudo, o $\mathrm{pH}$ de ambos os grupos foi acima de 5,9, não havendo nenhum efeito negativo da administração de tiroxina sobre esse parâmetro. Alguns pesquisadores também não encontraram alterações significativas no ganho de peso e nas características da carcaça de suínos não gestantes na fase final do crescimento tratados com tri-iodotironina (Wallace et al., 1959). Mas Yoshioka et al. (2005) sugeriram que as elevadas concentrações de tri-iodotironina (T3) em suínos, decorrentes da administração de cortisol, podem estar envolvidas na gênese da carne PSE. No entanto, no presente estudo, não foram observadas alterações musculares compatíveis com a carne PSE. Histologicamente o músculo de ambos os grupos apresentou características de normalidade. Também não houve diferença na composição do músculo das marrãs tratadas ou não com tiroxina, pois a porcentagem de fibras musculares e de estroma foi semelhante entre grupos (Tab. 3).

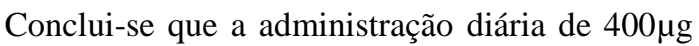
de tiroxina não altera o ganho de peso durante a gestação, o pH, a retenção de água e as características histológicas do músculo Longissimus dorsi de marrãs com 70 dias de gestação.

Tabela 1. Dosagem plasmática de T4 total $(\mu \mathrm{g} / \mathrm{dL})($ média \pm SD) de marrãs tratadas ou não com tiroxina antes da inseminação artificial, peso corporal inicial e final $(\mathrm{kg})$ e ganho de peso diário (g/dia) durante o experimento

\begin{tabular}{lrc}
\hline \multicolumn{1}{c}{ Variável } & Grupo-controle & \multicolumn{1}{c}{ Grupo tratado } \\
\hline T4 total $(\mu \mathrm{g} / \mathrm{dL})$ & $3,41 \pm 0,58 \mathrm{~b}$ & $4,53 \pm 0,85 \mathrm{a}$ \\
Peso corporal aos 120 dias de idade (início do & $70,08 \pm 12,61$ & $72,60 \pm 10,23$ \\
experimento) $(\mathrm{kg})$ & & \\
Peso corporal aos 70 dias de gestação $(\mathrm{kg})$ & $168,28 \pm 16,59$ & $170,09 \pm 11,67$ \\
Ganho de peso diário (g/dia) & $728,20 \pm 59,59$ & $740,50 \pm 71,60$ \\
\hline *Médias com letras minúsculas diferentes na linha diferem entre si (P<0,05).
\end{tabular}

Tabela 2. Área do halo $\left(\mathrm{cm}^{2}\right)$ de retenção de água, $\mathrm{pH}$ e temperatura (média $\left.\pm \mathrm{SD}\right)$ das amostras no músculo Longissimus dorsi de marrãs tratadas ou não com tiroxina e abatidas aos 70 dias de gestação

\begin{tabular}{lrr}
\hline Variável & Grupo-controle & Grupo tratado \\
\hline Área do halo $\left(\mathrm{cm}^{2}\right)$ & $3,08 \pm 2,48$ & $3,15 \pm 3,35$ \\
$\mathrm{pH}$ & $5,90 \pm 0,29$ & $5,92 \pm 0,20$ \\
Temperatura $\left({ }^{\circ} \mathrm{C}\right)$ & $31,86 \pm 0,69$ & $31,75 \pm 0,71$ \\
\hline
\end{tabular}

As médias não diferiram entre si $(\mathrm{P}>0,05)$.

Tabela 3. Porcentagem de fibras musculares e de estroma (média \pm SD) no músculo Longissimus dorsi de marrãs tratadas ou não com tiroxina e abatidas aos 70 dias de gestação

\begin{tabular}{lrr}
\hline Variável & Grupo-controle & Grupo tratado \\
\hline Músculo & $80,67 \pm 2,75$ & $77,69 \pm 3,48$ \\
Estroma & $19,33 \pm 2,75$ & $22,31 \pm 3,48$ \\
\hline As médias não diferiram entre si $(\mathrm{P}>0,05)$ &
\end{tabular}

Palavras-chave: Longissimus dorsi, tiroxina, hipertireoidismo, gestação, marrã 


\begin{abstract}
The effect of the thyroxine administration on body weight and on some physicochemical and histological characteristics of the Longissimus dorsi muscle was evaluated in gilts at 70 days of gestation. Twenty middle-sisters gilts, daughters of $F 1$ females with a 3/4 Landrace X $1 / 4$ Large White, male were used. At 150 days of age, i.e., before first heat, the animals were randomly distributed into two groups: treated ( $n$ $=10)$ and control $(n=10)$. The treated group received a daily dose of $400 \mu \mathrm{g}$ of L-thyroxine (T4) in the diet until three days before slaughter and the control group received only diet. Before artificial insemination, blood was collected for determination of plasma total T4. The gilts were inseminated in the second estrus and slaughtered at 70 days of gestation. The initial and final body weight, daily weight gain and $\mathrm{pH}$, water retention, and percentage of muscle fibers and stroma in the Longissimus dorsi muscle were studied. The means of all variables were compared by the Student t-test. Before insemination, the gilts showed clinical signs of hyperthyroidism, characterized by significant increase in plasma levels of T4, mild exophthalmos, and behavioral change characterized by aggression and agitation. There was not significant difference among groups according to the studied parameters. It was concluded that the daily administration of $400 \mu \mathrm{g}$ of thyroxine does not change the daily weight gain during the gestation, as well the $\mathrm{pH}$, the water retention, and the percentage of muscle fibers and stroma of the Longissimus dorsi muscle of gilts at 70 days of gestation.
\end{abstract}

Keywords: gilts, Longissimus dorsi, thyroxine, hyperthyroidism, gestation

\section{REFERÊNCIAS BIBLIOGRÁFICAS}

BOELAERT, K.; FRANKLYN, J.A. Thyroid hormone in health and disease. J. Endocrinol., v.187, p.1-15, 2005.

BRYHNI, E.A.; BYRNE, D.V.; RØDBOTTEN, M. et al. Consumer perceptions of pork in Denmark, Norway and Sweden. Food Quality Preference, v.13, p.257-266, 2002.

CARDOSO, M.J.L.; COSTA, F.S.; MUNIZ, L.M.R. et al. Manifestações clínicas em gatos com hipertireoidismo experimental. Arch. Vet. Sci., v. 10, p. 135-144, 2005.

CASSENS, R.G. Historical perspectives and current aspects of pork meat quality in the USA. Food Chem., v.69, p.357-363, 2000.

FREITAS, E.S.; LEITE, E.D.; SOUZA, C.A. et al. Histomorphometry and expressions of Cdc-47 and Caspase-3 in hyperthyroid rats uteri and placentas during gestation and postpartum associated with fetal development. Repr. Fertil. Dev., v.19, p.498-509, 2007.

HAYASHI, K.; TADA, O.; HIGUCHI, K. et al. Effects of corticosterone on connectin content and protein breakdown in rat skeletal muscle, Biosc. Biotechnol. Biochem., v.64, p.2686-2688, 2000.

ODEDRA, B.R.; BATES, P.C.; MILLWARD, D.J. Time course of the effect of catabolic doses of corticosterone on protein turnover in rat skeletal muscle and liver. Biochem. J., v.214, p.617-627, 1983.

PEO, E.R.; HUDMAN, D.B. Supplementation of pig starters with thyroprotein. J. Anim. Sci., v.19, p.477-483, 1960.

SANTOS, K.B.; VAISMAN, M.; FILHO, R.A.C. et al. Disfunção muscular esquelética e composição corporal no hipertireoidismo. Arq. Bras. Endocrinol. Metabol., v.46, p.626-631, 2002.

SERAKIDES, R.; NUNES, V.A.; NASCIMENTO, E.F. et al. Foliculogênese e esteroidogênese ovarianas em ratas adultas hipertireoideas. Arq. Bras. Endocrinol. Metabol., v.45, p.258-264, 2001.

SOUZA, C.A. Ovulação e desenvolvimento uterino, placentário e fetal em marrãs gestantes tratadas com tiroxina. 2009. 63f. Dissertação (Mestrado) - Escola de Veterinária, Universidade Federal de Minas Gerais, Belo Horizonte.

WALLACE, H.D.; NORRIS, C.E.; COMBS, G.E.; et al. Influence of triiodothyronine on feedlot performance and carcass characteristics of growing-finishing swine. J. Anim. Sci., v.18, p.1018-1024, 1959.

YOSHIOKA, G.; IMAEDA, N.; OHTANI, T. et al. Effects of cortisol on muscle proteolysis and meat quality in piglets. Meat Sci., v.71, p.590593, 2005. 